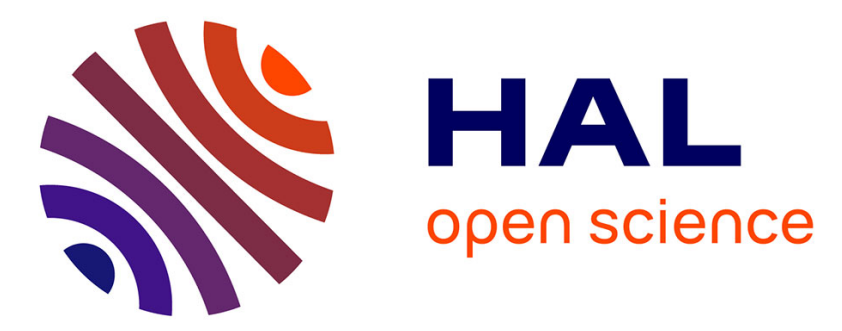

\title{
An exergetic approach for materials fatigue
}

\author{
Patrick Ribeiro, Diogo Queiros-Conde, Lavinia Grosu, Laurent Gallimard
}

\section{To cite this version:}

Patrick Ribeiro, Diogo Queiros-Conde, Lavinia Grosu, Laurent Gallimard. An exergetic approach for materials fatigue. International Journal of Exergy, 2017, 22 (3), pp.235 - 249. 10.1504/IJEX.2017.083172 . hal-01690130

\section{HAL Id: hal-01690130 \\ https://hal.parisnanterre.fr/hal-01690130}

Submitted on 22 Jan 2018

HAL is a multi-disciplinary open access archive for the deposit and dissemination of scientific research documents, whether they are published or not. The documents may come from teaching and research institutions in France or abroad, or from public or private research centers.
L'archive ouverte pluridisciplinaire HAL, est destinée au dépôt et à la diffusion de documents scientifiques de niveau recherche, publiés ou non, émanant des établissements d'enseignement et de recherche français ou étrangers, des laboratoires publics ou privés. 


\title{
An exergetic approach for materials fatigue
}

\section{Patrick Ribeiro*, Diogo Queiros-Condé, Lavinia Grosu and Laurent Gallimard}

\author{
LEME, \\ Université Paris-Ouest Nanterre La Défense, \\ 50 rue de Sèvres, \\ 92410 Ville d'Avray, France \\ Email: patrick.ribeiro@u-paris10.fr \\ Email: dqueiros-conde@u-paris10.fr \\ Email: lavinia.grosu@u-paris10.fr \\ Email: lgallima@u-paris10.fr \\ ${ }^{*}$ Corresponding author
}

\begin{abstract}
An entropy approach has been recently developed, based on the irreversible thermodynamics and entropy production. It has been observed that, for low cycle fatigue, metals undergoing cyclic load reach fracture, at a certain level of entropy production called fracture fatigue entropy (FFE) (Naderi and Khonsari, 2010), solely dependent on the material. Until now, we only used the two principles of thermodynamics separately to follow the behaviour of a solid continuum problem as low cycle fatigue. We propose here to use the two laws of thermodynamics together via the Gouy-Stodola equation and the concept of exergy to provide a new description for metals undergoing low cycle fatigue.
\end{abstract}

Keywords: fatigue; exergy; entropy; plastic deformation quality; fracture.

Reference to this paper should be made as follows: Ribeiro, P., Queiros-Condé, D., Grosu, L. and Gallimard, L. (2017) 'An exergetic approach for materials fatigue', Int. J. Exergy, Vol. 22, No. 3, pp.235-249.

Biographical notes: Patrick Ribeiro is currently a PhD student in Mechanical Engineering at the Université Paris Ouest Nanterre La Défense. He received his MS in Mechanical Engineering from the Université Paris XIII in 2014. His researches focus on classical thermodynamics, fatigue and fractals in collaboration with the LEME.

Diogo Queiros-Condé is Full Professor at the University Paris Ouest Nanterre la Défense in the Laboratory LEME (Lab. Energetics Mechanics Electromagnetism). He is doing research on turbulent combustion, turbulence, thermodynamics (exergy analysis) using fractal geometry, entropic skins geometry and the scale-entropy diffusion equation.

Lavinia Grosu graduated in Engineering at the University Polytechnic of Bucharest in 1996. She prepared her PhD thesis at LEMTA Laboratory of Nancy, on the subject of thermodynamic and economical optimisation of inverse cycle machines with two and three heat reservoirs. Since 2001, she has been a Lecturer at the University Nanterre, Paris. Her research tasks concentrate on the following: 
hot air engines (Stirling), Vuilleumier engines, finite dimensions thermodynamic applied to driving or receiving heat engines, energetical and exergetical analysis of heat exchangers and energetical optimisation.

Laurent Gallimard obtained his $\mathrm{PhD}$ in 1994 at Ecole Normale Supérieure de Cachan. He is currently a Professor at the University Paris Ouest Nanterre La Défense, and Head of the research team "Numerical and Theoretical Mechanics" in the LEME.

\section{Introduction}

Predicting the remaining life and the failure of a system is a society issue. Indeed, mechanical fatigue is responsible for many accidents like the tragic accident of Savigny-sur-Orge (France) in 2013 with the fatigue fracture of a splint implying the derailment of a train. Consequently, the field of fatigue mechanics is a domain of major interest for the research community.

Since the pioneering work of Whöler, many studies have been done to predict the number of cycles that a material can hold to failure. On cumulative damage (Miner, 1945; Coffin, 1971; Manson, 1964), empirical laws on low cycle fatigue (Morrow, 1965; Halford, 1966), on energy dissipation and strain energies of deformation (Park and Nelson, 2000) and on the bond between temperature, thermodynamics and fatigue (Lemaitre and Dufailly, 1987; Lemaitre and Chaboche, 1990; Fargione et al., 2002; Meneghetti, 2007).

The second law and more precisely, entropy, is through all its forms (Clausius entropy, Boltzmann entropy, Gibbs-Shannon entropy) well known and used in multiple domains. Thus, regarding the plastic deformation, and entropy through irreversible thermodynamics leads to a natural framework for studying fatigue. It has been shown that metals in low cycle fatigue possess a constant fracture fatigue entropy (FFE), solely dependent on the material (Khonsari and Amiri, 2012). This FFE represents the maximum accumulative entropy of the system. It is dependent on thermodynamic fluxes and forces involved in the process and informs us about the point of failure of a system.

In mechanical fatigue, the concepts of energy and entropy are used through the first and second principles. Exergy which can be expressed combining these two laws, represents the available energy, i.e., the mechanised fraction of the energy (Gouy, 1889; Stodola, 1903; Keenan, 1951; Rant, 1956). It defines the quality of an energy taking into account its environment and is used in the domain of engineering (Grosu, 2014; Grosu et al., 2004; Feidt, 2008; Pishbin et al., 2015) or natural resources (Valero Delgado, 2008; Hoque et al., 2015) where the use of this physical quantity is leading the way to a sustainable development through economy (Tsatsaronis, 2008) and is spreading increasingly to other domains (Talla Konchou et al., 2015; Sorgüven and Özilgen, 2015).

Order, disorder, thermodynamic entropy, multi-scale and fractal fatigue conduct to the question about if we consider the material dislocations being piloted by a fractal structure and its energetic events, What is the fractal representation of this energy flow (and its complementary)? and Where are the fractal support and its location? The field of fractals in materials is well documented (Carpinteri, 1994; Hähner et al., 1998) and the reflections about fractal geometry (Mandelbrot, 1975; Le Méhauté et al., 1998), entropy minimisation 
and constructal theory (Bejan, 2006; Wechsatol et al., 2004) and geometrical structure of entropy generation (Queiros-Condé, 2003; Queiros-Condé et al., 2015a, 2015b; Canivet et al., 2016) lead us to the exergy equation for a better understanding of mechanical fatigue.

In this paper, we present the new concept of exergy for low cycle fatigue pursuing the work on FFE of Khonsari and Amiri (2012) and papers related to the FFE (Naderi et al., 2010; Amiri and Khonsari, 2011; Naderi and Khonsari, 2010), in order to highlight new considerations in mechanical fatigue and plastic deformation using the idea of quality with exergy.

\section{Two thermodynamic principles for fatigue in materials}

The analysis is based on the two laws of thermodynamics applied to a sample during a fatigue test. The first principle of thermodynamics (conservation of energy) can be written by:

$$
\rho \dot{u}=-\operatorname{div} \dot{Q}+\sigma: D
$$

where $\rho$ is the density of the material, $\dot{Q}$ is the surface heat flux exchanged through the boundaries, $D$ the rate of deformation tensor (strain tensor per unit time), and $\sigma$ the stress tensor.

The second law adds the notion of inequality between heat and other types of energies like mechanical work. Moreover, irreversibility is highlighted through entropy, as a measure of disorder (more precisely level of micro-states):

$$
\rho \dot{s}=-\operatorname{div}\left(\frac{\dot{Q}}{T}\right)+\dot{\pi}
$$

where $\dot{s}$ is the specific entropy variation per unit time and $-\operatorname{div}\left(\frac{\dot{Q}}{T}\right)$ the specific entropy flow due to heat transfer (external entropy)

The specific entropy production rate $\dot{\pi}$ (internal entropy) characterises irreversible transformations (real transformations), thus, this term is always superior or equal to zero.

It comes simply:

$$
\rho \dot{s}+\frac{\operatorname{div} \dot{Q}}{T}-\left(\frac{\dot{Q}}{T^{2}} \cdot \nabla T\right) \geq 0
$$

And using equation (1) in equation (3):

$$
\rho \dot{s}+\frac{\sigma: D-\rho \dot{u}}{T}-\left(\frac{\dot{Q}}{T^{2}} \cdot \nabla T\right) \geq 0
$$

Now the Helmholtz free energy $\psi$ is introduced. It is a thermodynamic potential for the useful work obtainable by a closed system at temperature $T$ :

$$
\psi=u-T s
$$


The derivative with respect to time allows to obtain the expression of the entropy as a function of free energy:

$$
\dot{s}-\frac{\dot{u}}{T}=\frac{-1}{T}(\dot{\psi}+s \dot{T})
$$

And using equation (6) in equation (4) leads to:

$$
\underbrace{\frac{-\rho}{T}[(\dot{\psi}+s \dot{T})]+\frac{\sigma: D}{T}}_{\text {Mechanical term }}-\underbrace{\left(\frac{\dot{Q}}{T^{2}} \cdot \nabla T\right)}_{\text {Thermal term }} \geq 0 .
$$

This equation shows two sources of deviation of a reversible phenomenon, a mechanical part and a thermal part. In the mechanical part, the elastic component does not have an impact on the entropy production as it is a reversible phenomenon.

Assuming the fact that the system is submitted to small deformations, the linearisation of the deformation rate tensor into a total strain rate which is decomposed into plastic and elastic strain rate become possible:

$$
D=\dot{\epsilon}=\dot{\epsilon_{p}}+\dot{\epsilon_{e}} .
$$

The free energy rate can be written using the chain rule as a function of multiple variables (Lemaitre and Chaboche, 1990):

$$
\dot{\psi}=\frac{d \psi}{d \epsilon_{e}} \cdot \dot{\epsilon_{e}}+\frac{d \psi}{d T} \cdot \dot{T}+\frac{d \psi}{d V_{k}} \cdot \dot{V}_{k}
$$

$V_{k}$ : Set of internal variables related to internal phenomena at lower scales.

Finally, replacing equations (8) and (9) in equation (7):

$$
\begin{array}{r}
{\left[\frac{\left(\sigma-\rho \frac{d \psi}{d \epsilon_{e}}\right): \dot{\epsilon_{e}}}{T}\right]+\left[\frac{\sigma: \dot{\epsilon_{p}}}{T}\right]+\left[\frac{-\rho \dot{T}}{T}\left(s+\frac{d \psi}{d T}\right)\right]} \\
+\left[\frac{-\rho}{T}\left(\frac{d \psi}{d V_{k}} \dot{V}_{k}\right)\right]+\left(-\frac{\dot{Q}}{T^{2}} \cdot \nabla T\right) \geq 0 .
\end{array}
$$

Thanks to the work of Lemaitre and Chaboche (1990), this equation can be simplified using particular transformations:

- An elastic-reversible transformation without changes in internal variables and at constant and uniform temperature

$$
\sigma=\rho \frac{d \psi}{d \epsilon_{e}} .
$$

- An elastic homogeneous transformation without changes in internal variables and at a uniform temperature.

$$
s=-\frac{d \psi}{d T} .
$$


These relations, considered as state laws, attest for reversible transformations and do not contribute to generating entropy (with respect to the small strain hypothesis in equation (8)).

To simplify equations, the thermodynamic force $A_{k}$ related to the thermodynamic flux $\dot{V_{k}}$ is defined:

$$
A_{k}=\rho \frac{d \psi}{d V_{k}}
$$

Using equations (10)-(13), the equation of entropy production for materials fatigue can be retrieved:

$$
\dot{\pi}=\frac{\sigma: \dot{\epsilon_{p}}}{T}+\left(-\frac{A_{k} \dot{V}_{k}}{T}\right)+\left(-\frac{\dot{Q}}{T^{2}} \cdot \nabla T\right)>0
$$

$\frac{\sigma: \dot{\epsilon_{p}}}{T}$ : Entropy generation associated with mechanical power dissipated into plastic deformation.

$-\frac{A_{k} \dot{V}_{k}}{T}$ : Entropy generation associated with unrecoverable power stored in the material. $-\frac{\dot{Q}}{T^{2}} \cdot \nabla T:$ Entropy generation associated to heat flux.

The mechanical and thermodynamical approaches are different. For mechanical scientists, elastic transformations are reversible. In the point of view of thermodynamics, elastic transformations are real implying entropy production, and irreversibility (represented by the internal variables in this equation).

The simplest case to study is low cycle fatigue for metals, which implies the second and third term in equation (14) to be neglected (Lemaitre and Chaboche, 1990; Naderi et al., 2010):

$$
\left|\frac{A_{k} \dot{V}_{k}}{T}\right|<\left|\frac{\sigma: \dot{\epsilon_{p}}}{T}\right| \quad\left|\frac{\dot{Q}}{T^{2}} \cdot \nabla T\right|<<\left|\frac{\sigma: \dot{\epsilon_{p}}}{T}\right| .
$$

The entropy production reduces in this case to:

$$
\dot{\pi}=\frac{\sigma: \dot{\epsilon_{p}}}{T}>0
$$

$\sigma: \dot{\epsilon_{p}}$ represents the work of plastic deformation per unit time which can be approximated by empirical laws like Coffin-Manson, Morrow or Park \& Nelson's law.

The FFE is the accumulative maximum entropy that a material can hold, i.e., when the material reaches, its FFE, it breaks:

$$
\mathrm{FFE}=\int_{0}^{t_{f}}\left(\frac{\sigma: \dot{\epsilon_{p}}}{T}\right) \mathrm{d} t=\frac{N_{f} W_{c p}}{T}
$$

$t_{f}$ : Time to failure.

$N_{f}$ : Number of cycles to failure.

$W_{c p}$ : Cyclic Work of plastic deformation per unit volume.

Naderi et al. (2010) have demonstrated for Al-6061 T6 and SS 304 that their FFE was a property of the material, independent of any other parameter. 


\section{Coupling the first and second principles}

The use of the Helmholtz free energy permits to link the two principles (equations (1) and

(5)) (Lemaitre and Chaboche, 1990):

$$
\rho(\dot{\psi}+T \dot{s}+s \dot{T})=\sigma: D-\operatorname{div} \dot{Q} .
$$

Then using equations (9), (11)-(13) and using the small deformation hypothesis in equation (8) the expression becomes:

$$
A_{k} \dot{V_{k}}+\rho T \dot{s}=\sigma: \dot{\epsilon_{p}}-\operatorname{div} \dot{Q} .
$$

In addition, entropy can be expressed by:

$$
s=\frac{-d \psi}{d T}, \text { thus } \dot{s}=\frac{-d^{2} \psi}{d T d t} .
$$

Then using equations (9) and (11)-(13) $\dot{s}$ becomes:

$$
\dot{s}=\frac{-1}{\rho} \frac{d \sigma}{d T}: \dot{\epsilon}_{e}+\frac{d s}{d T} \dot{T}-\frac{1}{\rho} \frac{d A_{k}}{d T} \dot{V}_{k} .
$$

Now replacing $\dot{s}$ in equation (19), the following equation is obtained:

$$
\rho C \dot{T}=\sigma: \dot{\epsilon_{p}}-\operatorname{div} \dot{Q}-A_{k} \dot{V}_{k}+T\left(\frac{d \sigma}{d T}: \dot{\epsilon}_{e}+\frac{d A_{k}}{d T} \dot{V}_{k}\right) .
$$

With C, the specific heat: $C=T \frac{d s}{d T}=-T \frac{d^{2} \psi}{d T^{2}}$.

This equation shows the dependence of the temperature variation from classic macroscopic and internal variables. Furthermore, there are new thermo-coupled terms. The thermoelasticity phenomenon (reversible) and a thermo-coupled term related to internal variation (irreversible). This thermo-coupled term related to internal variation is an irreversible phenomenon that can be added to the thermoelastic phenomenon since an elastic deformation is not really reversible thermodynamically. This equation could be used for thermal fatigue dealing with thermal constraints.

Comparing the classical first principle used previously (equation (1)) and the equation obtained (equation (22)) leads to the equality:

$$
\sigma: \dot{\epsilon_{e}}=-A_{k} \dot{V}_{k}+T\left(\frac{d \sigma}{d T}: \dot{\epsilon}_{e}+\frac{d A_{k}}{d T} \cdot \dot{V}_{k}\right)
$$

Indicating the direct transformation of elastic deformation into internal and thermo-coupled variables and leading to the entropy production:

$$
\dot{\pi}=\frac{\sigma: D}{T}-\left(\frac{d \sigma}{d T}: \dot{\epsilon}_{e}+\frac{d A_{k}}{d T} \dot{V}_{k}\right)-\left(\frac{\dot{Q}}{T^{2}} \cdot \nabla T\right) .
$$

It is interesting to note that, assuming a steady-state during the fatigue test and using the two basic principles (equations (1) and (2)) leads to the same result (neglecting the thermocoupled terms), without the need of introducing the Helmholtz free energy. The disadvantage of this method is that the Helmholtz free energy is a linear combination of the two principles and is temperature dependent, whereas, the concept of exergy uses a constant environment temperature. 


\section{Exergy analysis of fatigue}

Exergy is defined as the maximum useful work obtainable from a system in contact with the environment or can be considered as a distance from equilibrium. Exergy analysis of the fatigue is applicable to every system submitted to mechanical and repetitive constraints. The fatigue exergy can be expressed as a simple linear combination of the first and second principle (considering the work of the ambient pressure on the material negligible):

$$
\rho \dot{x}=\rho\left(\dot{u}-T_{0} \dot{s}\right) \text {. }
$$

And replacing in equation (25), the internal energy variation and entropy variation from equations (1) and (2), the following equation is deduced:

$$
\rho \dot{x}=-\operatorname{div} \dot{Q}+\sigma: D+T_{0} \operatorname{div}\left(\frac{\dot{Q}}{T}\right)-\underbrace{T_{0} \dot{\pi}}_{\dot{x}_{d}}
$$

where $\dot{x}_{d}$ represents the exergy destruction flow. This quantity symbolises the generation of irreversibility, a deflection of the transformation from the reversibility. Using the entropy generation $\dot{\pi}$ (equation (14)), exergy balance becomes:

$$
\rho \dot{x}=\underbrace{-\operatorname{div} \dot{Q}\left(1-\frac{T_{0}}{T}\right)}_{\dot{x}_{q}}+\underbrace{\sigma: \dot{\epsilon_{p}}\left(1-\frac{T_{0}}{T}\right)}_{\dot{x}_{p}}+\underbrace{\sigma: \dot{\epsilon}_{e}}_{\dot{x}_{e}}-\underbrace{\left(-\frac{T_{0}}{T} A_{k} \dot{V}_{k}\right)}_{\text {in }_{k}}
$$

$\dot{x}_{e}: \quad$ Specific exergy flow associated to elastic deformation.

$\dot{x}_{q}$ : Specific exergy flow associated to heat transfer.

$\dot{x}_{p}: \quad$ Specific exergy flow associated to plastic deformation

an $_{k}$ : Specific energy flow associated to internal variables.

The equation obtained shows that the energy of plastic deformation, has a lower quality than the pure mechanical work. Its exergy corresponds to the second term of the exergy balance, it is an energy multiplied by the Carnot factor. Then, an interesting term is found associated with internal variables, which is pure energy. The dependence of the plastic deformation on temperature is evident through exergy analysis. The exergy related to plastic deformation can be interpreted as a quality of deformation, indeed, higher temperature implies more effective deformation and thus less material lifetime. For example, Hong et al. (2003), using experiments on a stainless steel 316L, for a constant plastic strain energy density varying the temperatures of the tests, obtains that the fatigue life at higher temperatures is smaller than the fatigue life at lower temperatures. In other words, for a same quantity of work, exergy deformation will be higher for a superior temperature and imply a better quality of deformation. If a machine could receive the energy accumulated during the fatigue of the material, it would get more energy (exergy) from a material's fatigue fracture at a higher temperature than a material's fracture at lower temperature.

The elastic deformation is viewed as pure mechanical work and so a 'noble' energy that confirms the mechanical definition of an elastic transformation (reversible). In fact, deformation, in general, is not reversible, consequently, to be in accordance with continuum mechanics the internal variables take into account these small scales phenomena and allows 
to be in agreement with very high cycle fatigue. Indeed, for solicitations under the yield strength, the deformation is quasi-elastic since plasticity appears at small scales. Internal damping, phase transition, dislocations ... are phenomena included in the internal variables. Above the yield strength, hardening appears and can be expressed with hardening variables $R \dot{p}$ and $X: \dot{\epsilon_{p}}$ cumulative plastic deformation and centre of displacement (Lemaitre and Chaboche, 1990). In terms of exergy balance, the pure irreversibility produced by the quasielastic transformation is related to the internal variables energy, which can be translated as a pure impossibility to produce work.

The exergy balance has the advantage to be a fraction of the energy, easier to represent and to use than entropy and entropy production. The Carnot factor represents precisely the coefficient of quality and imply the use of only a fraction of energy. The differences between energies are perceptible thanks to this approach ie the different energies are not directly added like the energy balance does, but their corresponding exergies are. For instance, the work of elastic deformation is fully recoverable whereas for heat and plastic deformation, only a part is recoverable. Since heat and plastic deformation have the same behaviour, we can illustrate plastic exergy as the maximum plastic work obtainable from a Carnot's machine operating between the environment and a plastic deformation source at temperature $T$ (see Figure 1).

Figure 1 Carnot's machine analogy of heat for the plastic deformation (see online version for colours)

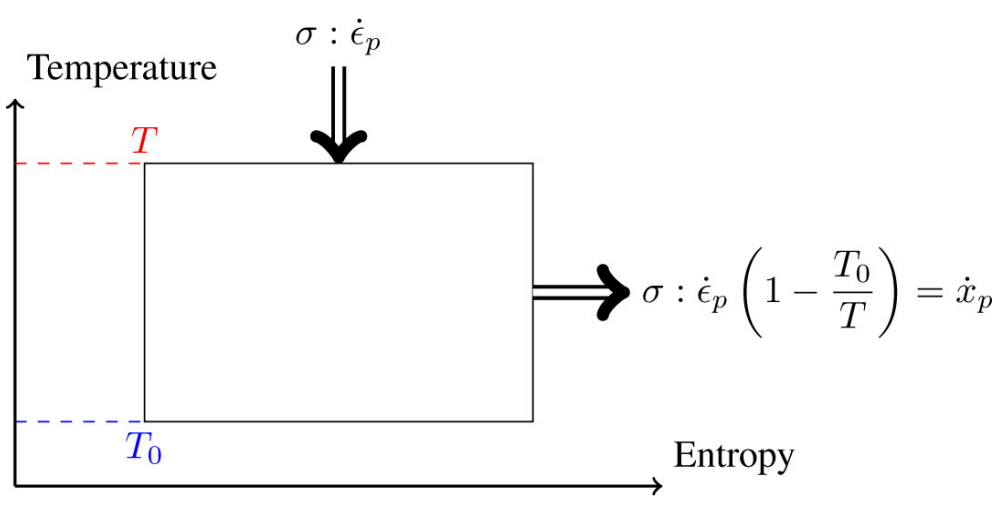

Another asset of using exergy comes from the fact that exergy destruction appears avoidable. Indeed, exergy destruction manifests itself through energy, thus, the control of temperature leads to the control of the degree of irreversibility. However, the limits of this control come from phase transitions and new material behaviours at higher temperatures integrated into internal variables. Another interesting expression is obtained using equations (26) and (24). It expresses the exergy with general deformation and thermo-coupled variables:

$$
\rho \dot{x}=-\operatorname{div} \dot{Q}\left(1-\frac{T_{0}}{T}\right)+\sigma: D\left(1-\frac{T_{0}}{T}\right)+T_{0}\left(\frac{d \sigma}{d T}: \dot{\epsilon}_{e}+\frac{d A_{k}}{d T} \dot{V}_{k}\right) .
$$

Here, we can see that the irreversibility comes from thermo-coupled-internal exergy destruction (last term in the equation) and that the deformation in a general definition (elastic and plastic) possesses a quality, plus a thermoelastic component, which seems to be a pure exergy, or a 'noble' energy. 


\section{Numerical applications for low cycle fatigue}

The numerical applications are based on the experiments of Naderi et al. (2010), Amiri and Khonsari (2011), Naderi and Khonsari (2010) for the Al-6061 T6 and the SS 304 in low cycle fatigue regime and with a solicitation ratio $R=-1$ (no mean stress). Materials and their properties are presented in Table 1.

Table 1 Fatigue properties of the Al-6061 T6 and the SS 304

\begin{tabular}{lcccccc}
\hline & $\sigma_{f}^{\prime}[\mathrm{MPa}]$ & $\varepsilon_{f}^{\prime}$ & $b$ & $c$ & $E[G P a]$ & $\nu$ \\
\hline Al-6061 T6 & 535 & 1.34 & -0.082 & -0.83 & 70 & 0.33 \\
SS 304 & 1000 & 0.171 & -0.114 & -0.402 & 185 & 0.29 \\
\hline
\end{tabular}

The temperature profiles and the number of cycles to failure are taken from the four tests done by Naderi and Khonsari (2010). Furthermore, the reference temperature will be taken equal to $T_{0}=288 \mathrm{~K}$. It represents the ambient temperature and can be set as the reference to compare multiple systems with an exergy balance. It permits to obtain the profile of the Carnot factor during the test. For the elastic and the plastic deformation, the Park \& Nelson's law permits a good evaluation of the work of each part (Park and Nelson, 2000) in order to calculate exergy, using the number of cycles to fracture $N_{f}$ :

$$
\begin{gathered}
\sigma: \epsilon_{p}=A N_{f}^{\alpha} \quad \sigma: \epsilon_{e}=B N_{f}^{\beta} \\
A=2^{2+b+c} \sigma_{f}^{\prime} \epsilon_{f}^{\prime}\left(\frac{c-b}{c+b}\right) \quad B=\frac{2^{2 b+1}(1+\nu)\left(\sigma_{f}^{\prime}\right)^{2}}{3 E} \quad \alpha=b+c \quad \beta=2 b .
\end{gathered}
$$

To simplify, we can hypothesise that the temperature is constant over the whole range of the test to calculate a constant Carnot factor $\theta$ (the two phases corresponding to the rise of temperature at the beginning and the end of the fatigue life represents very few cycles). We present in Table 2 experimental results and properties from the tests in Naderi et al. (2010), Amiri and Khonsari (2011) and Naderi and Khonsari (2010). Furthermore, using the loading frequency and replacing the Park \& Nelson model permits to obtain the plastic exergy, the exergy destruction (superscripts $\mathrm{c}$ for cyclic and superscript $\mathrm{T}$ for total) and the volumetric entropy production flow:

$$
\begin{aligned}
& x_{d}{ }^{T}=\int_{0}^{N_{f}} x_{d}{ }^{c}=\int_{0}^{N_{f}} \frac{T_{0}}{T} A N_{f}^{\alpha}=\frac{T_{0}}{T} A N_{f}^{\alpha+1} \\
& x_{p}{ }^{T}=\int_{0}^{N_{f}} x_{p}{ }^{c}=\int_{0}^{N_{f}}\left(1-\frac{T_{0}}{T}\right) A N_{f}^{\alpha}=\left(1-\frac{T_{0}}{T}\right) A N_{f}^{\alpha+1} \\
& \theta=1-\frac{T_{0}}{T} \quad \dot{\pi}=f \frac{A N_{f}^{\alpha}}{T} \quad \dot{x}_{d}=f x_{d}{ }^{c} \quad \dot{x}_{p}=f x_{p}{ }^{c}
\end{aligned}
$$

The results of the different tests of the Carnot factor, volumetric entropy production flow, plastic exergy and exergy destruction fluxes are presented in Figure 2 for the Al-6061 
T6 and Figure 3 for the SS 304. Fracture fatigue entropy, total exergy destruction and total plastic exergy dissipated over the whole life of the material are presented in Tables 3 and 4.

Table 2 Properties of the tests done by Naderi et al. (2010) for the Al-6061 T6 fatigue and Naderi and Khonsari (2010) for the SS 304 both at $f=10 \mathrm{~Hz}$

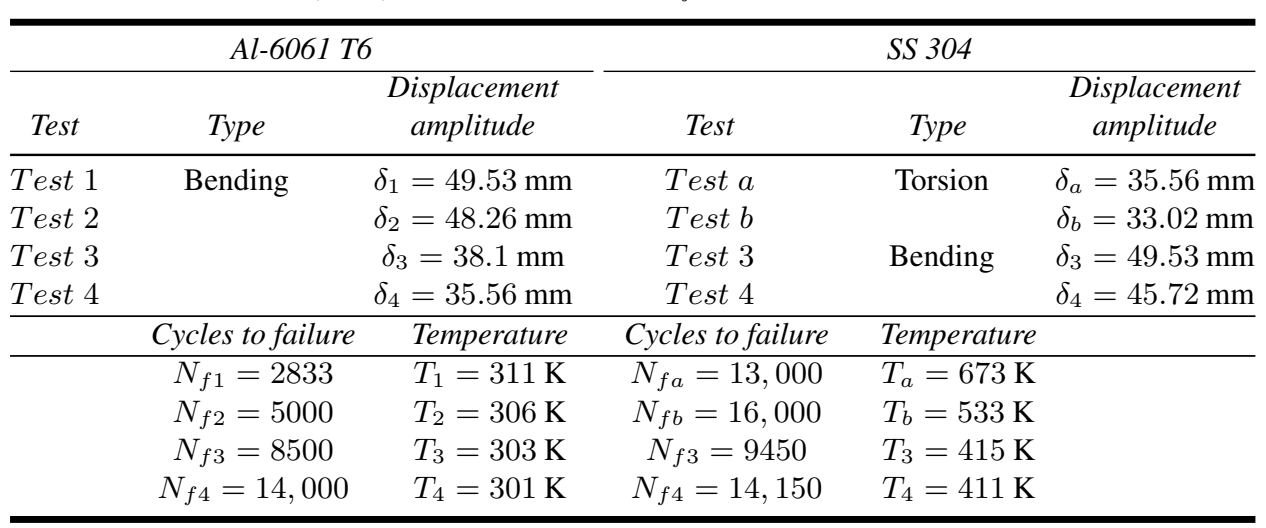

Figure 2 Results for the Al-6061 T6 (see online version for colours)
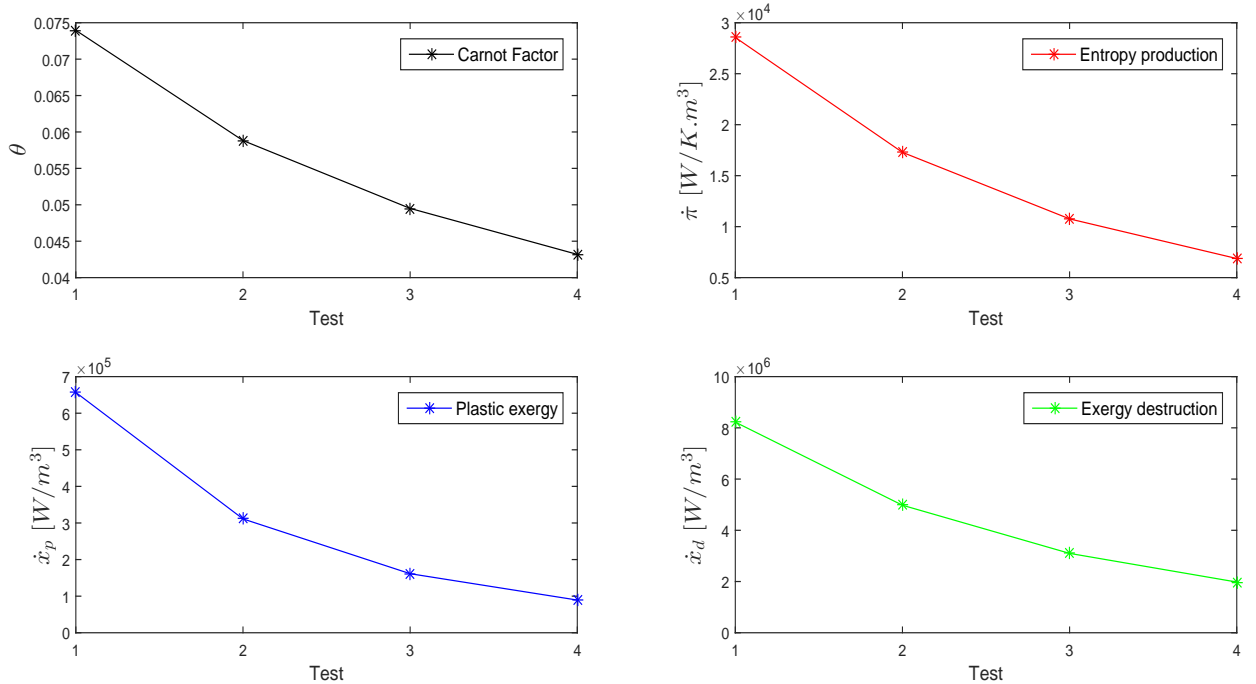

Some particular and interesting characteristics emerge from the results. The first concerns the FFE, which appears quasi-constant for low cycle fatigue for both materials. Likewise, total exergy destruction and the total plastic exergy seems constant, with a little perk, more stability about the constancy of these parameters. We can then observe for both materials submitted to bending fatigue that a decrease in displacement amplitude (deformation work) imply a decrease in the Carnot factor, entropy production flow, plastic exergy and exergy destruction. Since an ideal reversible transformation involve a null entropy production flux, lowering the displacement amplitude for bending fatigue implies a transformation closer 
to the ideal transformation which is traduced by less exergy destruction and less plastic exergy bringing logically to a higher fatigue life of the material (assuming the constancy of both total exergies such as the FFE), in other words, permitting to endure more cycles until the maximum accumulative entropy, the FFE (or the maximum accumulative exergy plastic or destruction). However, for torsion fatigue, the preceding interpretation is not verified. Besides the Carnot factor and the plastic exergy decrease, it is observed an increase in entropy production flux and in exergy destruction when the material is submitted to lower displacement amplitude (higher fatigue life). This comes from a greater importance of the Carnot factor in front of the plastic work in the entropy production flow compared to the bending fatigue (where the Carnot factor slightly changes compared to the plastic work). Furthermore, at high temperature, the material behaviour becomes more and more viscous which can lead to small strain hypothesis incompatibility and Park and Nelson incorrect estimation of the plastic work deformation (recalling that in the torsion cases $T / T_{\text {melting }}$ equals 0.4 (a) and 0.32 (b)). Nevertheless, a property between the different materials and type of fatigue is shared, it is the increase of the number of cycles to fracture when the plastic exergy diminishes, ie, when the quality of the plastic deformation declines implying the bond between the quality of deformation and fatigue life.

Figure 3 Results for the SS 304 (see online version for colours)
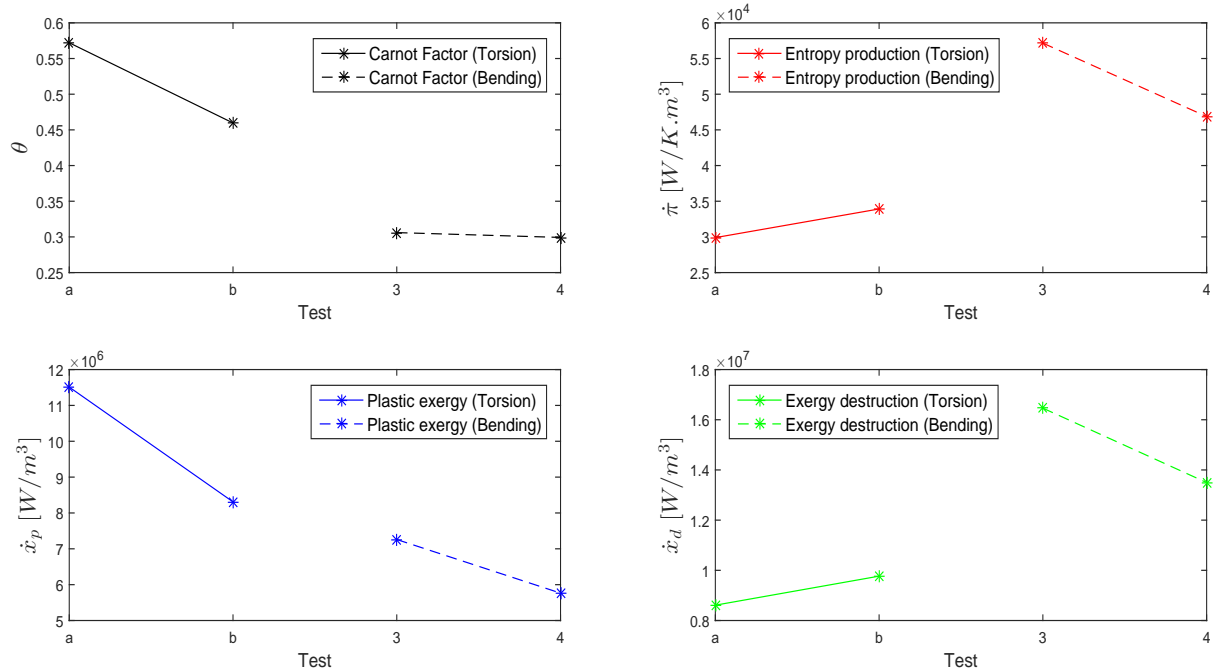

Table 3 FFE and exergies calculated over the whole test for the Al-6061 T6 $(f=10) \mathrm{Hz}$

\begin{tabular}{lcc}
\hline$F F E$ & Total exergy destruction & Total plastic exergy \\
\hline $8.09 \mathrm{MJ} / \mathrm{K} \cdot \mathrm{m}^{3}$ & $2.33 \mathrm{GJ} / \mathrm{m}^{3}$ & $0.186 \mathrm{GJ} / \mathrm{m}^{3}$ \\
$8.64 \mathrm{MJ} / \mathrm{Km}^{3}$ & $2.49 \mathrm{GJ} / \mathrm{m}^{3}$ & $0.156 \mathrm{GJ} / \mathrm{m}^{3}$ \\
$9.14 \mathrm{MJ} / \mathrm{K} \cdot \mathrm{m}^{3}$ & $2.63 \mathrm{GJ} / \mathrm{m}^{3}$ & $0.139 \mathrm{GJ} / \mathrm{m}^{3}$ \\
$9.62 \mathrm{MJ} / \mathrm{K} \cdot \mathrm{m}^{3}$ & $2.77 \mathrm{GJ} / \mathrm{m}^{3}$ & $0.125 \mathrm{GJ} / \mathrm{m}^{3}$ \\
\hline$\overline{F F E}$ & $\overline{x_{d}^{T}}$ & $\overline{x_{p}^{T}}$ \\
\hline $8.87 \mathrm{MJ} / \mathrm{K} \cdot \mathrm{m}^{3}$ & $2.56 \mathrm{GJ} / \mathrm{m}^{3}$ & $0.152 \mathrm{GJ} / \mathrm{m}^{3}$ \\
\hline
\end{tabular}


Table 4 FFE and exergies calculated over the whole test for the SS $304(f=10 \mathrm{~Hz})$

\begin{tabular}{lcc}
\hline FFE & Total exergy destruction & Total plastic exergy \\
\hline $38.87 \mathrm{MJ} / \mathrm{K} . \mathrm{m}^{3}$ & $11.19 \mathrm{GJ} / \mathrm{m}^{3}$ & $14.96 \mathrm{GJ} / \mathrm{m}^{3}$ \\
$54.27 \mathrm{MJ} / \mathrm{K} . \mathrm{m}^{3}$ & $15.63 \mathrm{GJ} / \mathrm{m}^{3}$ & $13.30 \mathrm{GJ} / \mathrm{m}^{3}$ \\
$54.02 \mathrm{MJ} / \mathrm{K} \cdot \mathrm{m}^{3}$ & $15.56 \mathrm{GJ} / \mathrm{m}^{3}$ & $6.86 \mathrm{GJ} / \mathrm{m}^{3}$ \\
$66.31 \mathrm{MJ} / \mathrm{K} \cdot \mathrm{m}^{3}$ & $19.10 \mathrm{GJ} / \mathrm{m}^{3}$ & $8.156 \mathrm{GJ} / \mathrm{m}^{3}$ \\
\hline$\overline{\mathrm{FFE}}$ & $\overline{x_{d}^{T}}$ & $\overline{x_{p}^{T}}$ \\
\hline $53.37 \mathrm{MJ} / \mathrm{K} . \mathrm{m}^{3}$ & $15.37 \mathrm{GJ} / \mathrm{m}^{3}$ & $10.82 \mathrm{GJ} / \mathrm{m}^{3}$ \\
\hline
\end{tabular}

\section{Conclusion}

Based on thermodynamics analysis of low cycle fatigue (Khonsari and Amiri, 2012), and the notion of FFE which seems to only depend on the material, it has been demonstrated through the Gouy-Stodola equation (the exergy balance) that plastic deformation can be considered as a 'degraded energy' like the classical heat energy. This plastic exergy is a measure of the quality of the plastic deformation and consequently, measures the dependence of the material life on the temperature and its environment through the Carnot factor (quality factor). The energy quality (exergy) increases with the Carnot factor, but the interpretation for plastic deformation is different from heat energy. As the exergy of heat, the exergy of plastic work deformation corresponds to the maximum efficient use for plastic deformation. But, the more efficient the energy of deformation, the less the material lifetime. In the specific case of low cycle fatigue, the plastic work deformation is the principal source of irreversibility. High and very high cycle fatigue display the two other sources of irreversibility: internal variables and heat. The very high cycle fatigue uses stress below the yield strength, involving pure reversible elastic transformations and leading, from a theoretical mechanical point of view to an infinite life of the material. However, from a thermodynamical approach, very high cycle fatigue is a succession of elastic transformations, accompanied by an entropy generation and implies a finite life of the material. Thus, according to thermodynamical considerations, the fatigue limit (corresponding to a fatigue limit stress where below, the material, in theory, would have an infinite life) doesn't seem to exist (for example, Bathias et al. (2001), Wang et al. (1999a, 1999b) and Zuo et al. (2008)), strengthening the idea of a thermodynamical framework for fatigue. Exergy, dealing with the study of a system with its environment could be very useful for fatigue (highly sensitive on environmental conditions) in the characterisation of a material's lifetime, furthermore, the quality of an elastic transformation and the energy-related to internal variables can lead to a new perspective in high and very cycle fatigue.

\section{References}

Amiri, M. and Khonsari, M.M. (2011) 'On the role of entropy generation in processes involving fatigue', Entropy, Vol. 14, No. 1, pp.24-31. 
Bathias, C., Drouillac, L. and François, P.L. (2001) 'How and why the fatigue S-N curve does not approach a horizontal asymptote', International Journal of Fatigue, Vol. 23, Supplement 1, pp.143-151.

Bejan, A. (2006) Advanced Engineering Thermodynamics, Wiley, New Jersey.

Canivet, Y., Queiros-Condé, D. and Grosu, L. (2016) 'Fractal representation of exergy', Entropy, Vol. 18, No. 2, p.56.

Carpinteri, A. (1994) 'Fractal nature of material microstructure and size effects on apparent mechanical properties', Mechanics of Materials, Vol. 18, No. 2, pp.89-101.

Coffin, L.F. (1971) 'A note on low cycle fatigue laws', Journal of Materials, Vol. 6, No. 2, pp.388-402.

Fargione, G., Geraci, A., Rosa, G.L. and Risitano, A. (2002) 'Rapid determination of the fatigue curve by the thermographic method', International Journal of Fatigue, Vol. 24, No. 1, pp.11-19.

Feidt, M.L. (2008) 'Optimal use of energy systems and processes', International Journal of Exergy, Vol. 5, Nos. 5006, pp.500-531.

Gouy, M. (1889) 'Sur l'énergie utilisable', Journal de physique théorique et appliquée, Vol. 8, No. 1, pp.501-518.

Grosu, L. (2014) Exergie et systèmes énergétiques: Transition vers l'exergétique, Presses Académiques Francophones.

Grosu, L., Feidt, M. and Benelmir, R. (2004) 'Study of the improvement in the performance coefficient of machines operating with three reservoirs', International Journal of Exergy, Vol. 1, No. 1, pp.147-162.

Hähner, P., Bay, K. and Zaiser, M. (1998) 'Fractal dislocation patterning during plastic deformation', Phys. Rev. Lett., Vol. 81, pp.2470-2473.

Halford, G.R. (1966) 'The energy required for fatigue', Journal of Materials, Vol. 1, pp.3-18.

Hong, S-G., Yoon, S. and Lee, S-B. (2003) 'The effect of temperature on low-cycle fatigue behavior of prior cold worked 3161 stainless steel', International Journal of Fatigue, Vol. 25, Nos. 9-11, pp.1293-1300.

Hoque, M.R., Villalba Méndez, G., Gabarell Durany, X. and Sala, C.S. (2015) 'Exergy analysis of construction material manufacturing processes and assessment of their improvement potentials', International Journal of Exergy, Vol. 16, No. 1, pp.22-52.

Keenan, J. (1951) 'Availability and irreversibility in thermodynamics', British Journal of Applied Physics, Vol. 2, No. 7, pp.183-192.

Khonsari, M.M. and Amiri, M. (2012) Introduction to Thermodynamics of Mechanical Fatigue, CRC Press, Boca Raton.

Le Méhauté, A., Nigmatullin, R. and Nivanen, L. (1998) Flèche du temps et géométrie fractale, Hermes Science Publications, Paris.

Lemaitre, J. and Chaboche, J. (1990) Mechanics of Solid Materials, Cambridge, UK.

Lemaitre, J. and Dufailly, J. (1987) 'Damage measurements', Engineering Fracture Mechanics, Vol. 28, pp.643-661.

Mandelbrot, B. (1975) Les objets fractals : forme, hasard et dimension, Flammarion.

Manson, S.S. (1964) 'Interpretive report on cumulative fatigue damage in the low cycle range', Welding Journal Research, Vol. 43, 344-352.

Meneghetti, G. (2007) 'Analysis of the fatigue strength of a stainless steel based on the energy dissipation', International Journal of Fatigue, Vol. 29, pp.81-94. 
Miner, M.A. (1945) 'Cumulative damage in fatigue', Journal of Applied Mechanics, Vol. 67, pp.159-164.

Morrow, J. (1965) 'Cyclic plastic strain energy and fatigue of metals', ASTM STP, Vol. 378, pp.45-87.

Naderi, M. and Khonsari, M.M. (2010) 'An experimental approach to low-cycle fatigue damage based on thermodynamic entropy', International Journal of Solids and Structures, Vol. 47, No. 6, pp.875-880.

Naderi, M., Amiri, M. and Khonsari, M.M. (2010) 'On the thermodynamic entropy of fatigue fracture', Proceedings of the Royal Society A: Mathematical, Physical and Engineering Science, Vol. 466, No. 2114, pp.423-438.

Park, J. and Nelson, D. (2000) 'Evaluation of an energy based approach and a critical plane approach for predicting constant amplitude multiaxial fatigue life', International Journal of Fatigue, Vol. 22, pp.23-39.

Pishbin, S.I., Ghazikhani, M. and Razavi, S. M.R.M. (2015) 'Experimental study on the effects of flame regime on the exergy destruction in premixed low swirl combustion', International Journal of Exergy, Vol. 17, No. 3, pp.267-286.

Queiros-Condé, D., Carlier, J., Grosu, L. and Stanislas, M. (2015a), 'Entropic-skins geometry to describe wall turbulence intermittency', Entropy, Vol. 17, No. 4, pp.2198.

Queiros-Condé, D., Chaline, J. and Dubois, J. (2015b) Le monde des fractales - La nature transéchelle, Ellipses Marketing.

Queiros-Condé, D. (2003) 'A diffusion equation to describe scale-and time-dependent dimensions of turbulent interfaces', Proceedings of the Royal Society of London A: Mathematical, Physical and Engineering Sciences, Vol. 459, No. 2040, pp.3043-3059.

Rant, Z. (1956) 'Exergie, ein neues wort fur technische arbeitsfahigkeit', Forsch. Ing. Wes., Vol. 22, No. 1, pp.36-37.

Sorgüven, E. and Özilgen, M. (2015) 'First and second law work production efficiency of a muscle cell', International Journal of Exergy, Vol. 18, No. 2, pp.142-156.

Stodola, A. (1903) Die Dampfturbinen und die Aussichten der Wärmekraftmaschinen.

Talla Konchou, F.A., Aloyem Kaze, C.V. and Tchinda, R. (2015) 'An application of energy and exergy analysis at the transportation sector of Cameroon', International Journal of Exergy, Vol. 18, No. 2, pp.129-141.

Tsatsaronis, G. (2008) 'Recent developments in exergy analysis and exergoeconomics', International Journal of Exergy, Vol. 5, Nos. 5-6, pp.489-499.

Valero Delgado, A. (2008) Exergy Evolution of the Mineral Capital on Earth, PhD Thesis, University of Zaragoza.

Wang, Q.Y., Berard, J.Y., Dubarre, A., Baudry, G., Rathery, S. and Bathias, C. (1999a) 'Gigacycle fatigue of ferrous alloys', Fatigue and Fracture of Engineering Materials and Structures, Vol. 22, No. 8, pp.667-672.

Wang, Q.Y., Berard, J.Y., Rathery, S. and Bathias, C. (1999b) 'Technical note high-cycle fatigue crack initiation and propagation behaviour of high-strength sprin steel wires', Fatigue and Fracture of Engineering Materials and Structures, Vol. 22, No. 8, pp.673-677.

Wechsatol, W., Lorente, S. and Bejan, A. (2004) 'Tree-shaped flow structures: are both thermalresistance and flow-resistance minimisations necessary?', International Journal of Exergy, Vol. 1, No. 1, pp.2-17.

Zuo, J., Wang, Z. and Han, E. (2008) 'Effect of microstructure on ultra-high cycle fatigue behavior of Ti-6Al-4V', Materials Science and Engineering: A, Vol. 473, No. 1-2, pp.147-152. 


\section{Nomenclature}

\begin{tabular}{|c|c|c|}
\hline$\overline{A, B}$ & Park \& Nelson coefficients & $\mathrm{Pa}$ \\
\hline$a \dot{n}_{k}$ & Specific energy flow associated to internal variables & W.m ${ }^{-3}$ \\
\hline$A_{k}$ & Thermodynamical force associated to internal variables & $\mathrm{J} . \mathrm{m}^{-3}$ \\
\hline$b$ & Fatigue strength exponent & - \\
\hline$c$ & Fatigue ductility exponent & _- \\
\hline$C$ & Specific heat & $\mathrm{J} \cdot \mathrm{kg}^{-1} \cdot \mathrm{K}^{-1}$ \\
\hline$D$ & Rate of deformation tensor (strain tensor per unit time) & $\mathrm{s}^{-1}$ \\
\hline$E$ & Young modulus & $\mathrm{Pa}$ \\
\hline$f$ & Frequency & $\mathrm{Hz}$ \\
\hline FFE & Fracture fatigue entropy & $\mathrm{J} \cdot \mathrm{m}^{-3} \cdot \mathrm{K}^{-1}$ \\
\hline$N_{f}$ & Number of cycles to failure & - \\
\hline$\dot{Q}$ & Surface heat flux & $\mathrm{W} \cdot \mathrm{m}^{-2}$ \\
\hline$\dot{s}$ & Specific entropy flux & $\mathrm{W} \cdot \mathrm{kg}^{-1} \cdot \mathrm{K}^{-1}$ \\
\hline$s$ & Specific entropy & $\mathrm{J} \cdot \mathrm{kg}^{-1} \cdot \mathrm{K}^{-1}$ \\
\hline$t_{f}$ & Time to failure & s \\
\hline$\dot{T}$ & Absolute temperature variation & K \\
\hline$T$ & Absolute temperature & $\mathrm{K}$ \\
\hline$T_{0}$ & Absolute environment temperature & $\mathrm{K}$ \\
\hline$\dot{u}$ & Specific internal power & W. $\mathrm{kg}^{-1}$ \\
\hline$u$ & Specific internal energy & ${\mathrm{J} . \mathrm{kg}^{-1}}^{-1}$ \\
\hline$\dot{V}_{k}$ & Rate of variation of internal variables & J.m ${ }^{-3}$ \\
\hline$\dot{W}$ & Work of deformation per unit time & W.m ${ }^{-3}$ \\
\hline$W_{c p}$ & Cyclic plastic work & $\mathrm{J}$ \\
\hline$\dot{x}$ & Specific exergy flux & W. $\mathrm{kg}^{-1}$ \\
\hline$\dot{x}_{d}$ & Specific exergy destruction flux & W.m ${ }^{-3}$ \\
\hline$\dot{x}_{e}$ & Specific exergy flow associated to elastic deformation & W.m $\mathrm{m}^{-3}$ \\
\hline$\dot{x}_{p}$ & Specific exergy flow associated to plastic deformation & W.m ${ }^{-3}$ \\
\hline$\dot{x}_{q}$ & Specific exergy flow associated to heat transfer & W.m $m^{-3}$ \\
\hline$x_{d}^{c}$ & Cyclic exergy destruction & J. $\mathrm{m}^{-3}$ \\
\hline$x_{d}^{T}$ & Total exergy destruction & J.m $\mathrm{m}^{-3}$ \\
\hline$x_{p}{ }^{c}$ & Cyclic plastic exergy & J.m $\mathrm{m}^{-3}$ \\
\hline$x_{p}^{T}$ & Total plastic exergy & J.m $\mathrm{m}^{-3}$ \\
\hline \multicolumn{3}{|c|}{ Greek symbols } \\
\hline$\alpha, \beta$ & Park \& Nelson exponents & - \\
\hline$\epsilon_{f}^{\prime}$ & Fatigue ductility coefficient & - \\
\hline$\dot{\epsilon_{e}}$ & Elastic strain rate & $\mathrm{s}^{-1}$ \\
\hline$\dot{\epsilon_{p}}$ & Plastic strain rate & $s^{-1}$ \\
\hline$\dot{\epsilon}$ & Total strain rate & $\mathrm{s}^{-1}$ \\
\hline$\eta$ & Efficiency & - \\
\hline$\nu$ & Poisson's ratio & _- \\
\hline$\dot{\pi}$ & Entropy generation flow & $\mathrm{W} \cdot \mathrm{m}^{-3} \cdot \mathrm{K}^{-1}$ \\
\hline$\dot{\psi}$ & Helmholtz specific free energy flux & W. $\mathrm{kg}^{-1}$ \\
\hline$\psi$ & Helmholtz specific free energy & J.kg ${ }^{-1}$ \\
\hline$\rho$ & Material density & $\mathrm{kg} \cdot \mathrm{m}^{-3}$ \\
\hline$\sigma_{f}^{\prime}$ & Fatigue strength coefficient & $\mathrm{Pa}$ \\
\hline$\sigma$ & Stress tensor & J.m $\mathrm{m}^{-3}$ \\
\hline$\theta$ & Carnot factor & - \\
\hline
\end{tabular}

